\title{
A study of serum monoamine oxidase (MAO) activity and the EEG in nickel carbonyl workers
}

\author{
SHI ZHICHENG, A LATA, AND HAN YUHUA \\ From the Department of Occupational Medicine, Third Hospital, Beijing Medical College, Beijing, China
}

There are few reports of the chronic effects of exposure to relatively low levels of nickel carbonyl. The purpose of the present study was to measure serum monoamine oxidase (MAO) activity and examine EEG in nickel carbonyl workers and to determine if any abnormalities were present.

\section{Subjects and methods}

Seventy six nickel carbonyl workers (54 male and 22 female) were studied. They were divided into two groups of exposure. Group A consisted of 42 subjects whose exposure ranged from 10 to 20 years; their average age was $36 \cdot 2$ years (range $32-54$ ). Group B consisted of 36 subjects with exposure ranging from two to eight years; their average age was $29 \cdot 1$ years (range $20-42)$. In addition, 40 healthy workers $(20$ male and 20 female) with no exposure to nickel carbonyl served as controls (group C). Their average age was 28.4 years (range $21-36$ ).

The airborne concentration of nickel carbonyl ranged from $0.007 \mathrm{mg} / \mathrm{m}^{3}$ to $0.52 \mathrm{mg} / \mathrm{m}^{3}$.

MAO activity in the serum was measured using an ammonia specific electrode method as modified by Proelss. $^{1}$ 2-(Para-aminomethylphenyl) azonaphthol was used as substrate and the activity was calculated in units per $\mathrm{ml}$, warmed to $37^{\circ} \mathrm{C}$ in one hour.

The EEG was examined by the routine method used in clinical practice.

\section{Results}

The data obtained for the three groups are summarised in tables 1 and 2.

Both groups of workers had decreased mean SMAO values compared with the controls. The difference between the results in groups $A$ and $C$ was significant $(p<0.01)$ as was that between groups $A$ and $B(p<0.05)$; there was no significant difference $(p>0.05)$ between the results in groups B and C, however. Both groups $\mathrm{A}$ and $\mathrm{B}$ had an increased rate of EEG abnormalities compared with the controls. The differences between groups $\mathbf{A}$ and $\mathbf{B}$ and groups $A$ and $C$ were highly significant $(p<0.01)$, but there was no significant difference between the rates in groups $B$ and $C(p>0.05)$.

The EEG changes were characterised by the predominance of diffuse $\theta$ activity in some regions which was longer than normal, irregular, or very unstable $\alpha$ activity, and sometimes high voltage $\beta$ activity.

Eight subjects $(19 \cdot 1 \%)$ in group $A$ had both an abnormal EEG and a low level of MAO activity (mean - $1 \mathrm{SD}$ ).

\section{Discussion}

Exposure to high concentrations of nickel carbonyl may result in acute poisoning which causes damage to the respiratory and nervous systems. We have also found that long term exposure to low concentrations of nickel carbonyl may produce symptoms such as excitement, sleeplessness, altered dreaming, headache, dizziness, weakness, poor memory, tightness in the chest, polyhidrosis, loss of hair, and sexual frigidity. The incidence and severity of these symptoms is increased with an increase in the duration of exposure. In the present paper we show that the mean value of SMAO activity in group A was much lower than that

Table 1 Comparison of $S M A O$ results (mean $\pm S D$ )

\begin{tabular}{lll}
\hline Group & No of cases & $S M A O(\mu / \mathrm{ml})$ \\
\hline A & 42 & $3 \cdot 23 \pm 2 \cdot 37(0-12 \cdot 8)$ \\
B & 36 & $4 \cdot 66 \pm 2 \cdot 81(1 \cdot 7-15 \cdot 9)$ \\
C & 40 & $5 \cdot 24 \pm 4 \cdot 07(2-14 \cdot 3)$ \\
\hline
\end{tabular}

Table 2 Comparison of EEG results of groups

\begin{tabular}{|c|c|c|c|}
\hline \multirow[t]{2}{*}{ Group } & \multirow[t]{2}{*}{ No of cases } & \multicolumn{2}{|c|}{ Abnormalities EEG } \\
\hline & & No & $\%$ \\
\hline $\begin{array}{l}\mathbf{A} \\
\mathbf{B} \\
\mathbf{C}\end{array}$ & $\begin{array}{l}42 \\
36 \\
40\end{array}$ & $\begin{array}{r}18 \\
5 \\
4\end{array}$ & $\begin{array}{l}42.9 \\
13.9 \\
10.0\end{array}$ \\
\hline
\end{tabular}


in the control group $C(p<0.01)$ and lower than that in group $B(p<0.05)$. The rate of EEG abnormalities in group $A$ was also significantly higher than in group B $(p<0.01)$. In addition, the decrease in SMAO activity was parallel to the rate of abnormality in the EEG in group $A$.

In man there is high activity of MAO in the brain, liver, kidney, heart, adrenals, and intestine.$^{2}$ It is distributed widely in the central nervous system and in the peripheral sympathetic nervous system, particularly in sympathetic nerve endings. MAO is located on the outer membrane of the mitochondrion and catalyses the oxidative deamination of monoamines and 5-hydroxytryptamine, which are important neuro transmitters. ${ }^{3}$

Our results suggest that some degree of biochemical and electrophysiological change in the nervous system develops in workers with long term exposure to low levels of nickel carbonyl.

We consider that MAO activity and the EEG may $\underset{\mathbb{Q}}{2}$ be used as objective indices for the dynamic obser-? vation on the chronic influence of exposure to nickel carbonyl.

\section{References}

${ }^{1}$ Proelss HF, Wright BW. Rapid determination of ammonia in a $\vec{\omega}$ perchloric acid supernation from blood, by use of an ammoniaspecific electrode. Clin Chem 1973;19:1162-9.

${ }^{2}$ Sandler M, Youdim MBH. Multiple forms of monoamine oxidase: functional significance. Pharmacol Rev 1972;24:331-48.

${ }^{3}$ Costa F, Sandler M. Monoamine oxidase-new vistas. In: Advances $\vec{\omega}$ in biochemical psychopharmacology. Vol 5. New York: Raven, 1972:42-58. 